\title{
An Investigation of Thermal Elasto-Plastic Stress Analysis of Laminated Thermoplastic Composites with a Circular Hole under Uniform Temperature Loading
}

\author{
Faruk Sen \\ Department of Mechanical Engineering, Faculty of Engineering, \\ Dokuz Eylul University, Bornova, Izmir 35100, Turkey
}

\begin{abstract}
This investigation was performed to study the response of a thermal elasto-plastic stress analysis and residual stresses on symmetric cross ply $[0 / 90]_{\mathrm{s}}$ and angle-ply $[30 /-30]_{\mathrm{s}},[45 /-45]_{\mathrm{s}},[60 /-60]_{\mathrm{s}}$ steel fiber reinforced thermoplastic laminated plate, which is subjected to a uniform temperature load with a circular hole. To evaluate the effects of uniform temperature value and stacking sequence of the laminated thermoplastic composite plates on the thermal stress, the study was carried out using the finite element solution. For this purpose the solution was calculated by ANSYS analysis code. The width to diameter (L/D) ratio in the plate was selected as 10 . The composite materials were assumed to be linearly hardening. The Tsai-Hill theory was used as a yield criterion. Thermoplastic laminated composite plates were simply supported. All thermal stress values depending on applied temperature are shown in tables. It was found that increasing uniform temperature values and stacking sequence of composite plates considerably affected thermal stresses.
\end{abstract}

Key words: Thermal stress analysis, Laminated composites, Finite element method (FEM), Thermoplastic composites

\footnotetext{
'Tel:+90-232-388 3138/110

Fax:90-232-388 7868

E-mail address: faruk.sen@deu.edu.tr

Internet: http://www.deu.edu.tr
}

\section{INTRODUCTION}

Availability of the new, low cost, high performance fiber reinforced plastic (FRP) structural composites for infrastructure construction and rehabilitation has given an impetus to the development of a new technology in the construction industry. In infrastructure the applications of the forms of FRP range from strengthening concrete columns, piles, piers, beams, decks, and other concrete structures to using high strength cables or tendons for prestressing or posttensioning of concrete columns or beams and using the steel rebar profiled reinforcing FRP rods, gratings of different profiles and sections, continuous-fiber isogrids for imbedded concrete reinforcement, external wrappings of columns, or simple bonding of FRP plates to the concrete structure. Inherent lightness, placement flexibility, corrosion resistance, high strength to weight ratio, low relaxation/creep, high fatigue resistance, and magnetic transparency of FRP composites make them attractive as logical substitutes for steel structural elements $/ 1 \%$ Thermal stresses are important in engineering design since they can lead to premature failure or plastic yielding in structures $/ 2 /$. Laminates, like many structures, must have holes to serve various purposes. An obvious purpose is to accommodate a bolt. Another purpose is to provide access from one side of 
the laminate to the other. The analysis of the stresses around holes is quite difficult $13 /$. Thermal stress analyses for bars, beams, plates and cylinders are more. easily understandable $/ 4 /$.

Sayman /2/ carried out a thermal elastic-plastic and residual stress analysis on symmetric cross-ply and angle ply thermoplastic laminated plates. In that study temperature changed linearly along the cross sections of the plates. Wang et al. /5/ offered an analytical method in order to determine the thermal residual stresses in an isotropic plate reinforced with a circular orthotropic patch. Akay and Ozden /6/ obtained thermal residual stresses in injection-moulded thermoplastics by removing thin layers from specimens. Sayman et al. /7/ carried out elastic-plastic stress analysis on a steel-fiberreinforced high-density thermoplastic composite cantilever beam loaded by a bending moment at its free end. Sayman and Esendemir /8/ presented a low density polyethylene thermoplastic composite reinforced by woven steel fibers supported at the ends acted upon with a force at the midpoint. Jeronimidis and Parkyn /9/ studied residual stresses in carbon fiber-thermoplastic matrix laminates. Sayman and Kayrici $/ 10 /$ studied elasto-plastic stress analysis on a thermoplastic composite cantilever beam subjected to a single transverse force applied to the free and of the beam. Senel et al. /11/ performed residual stress analysis of laminated composite plates under thermal loads using analytical methods. Chung $/ 12 /$ studied the thermal analysis of carbon fiber polymer-matrix composites by electrical resistance measurement. Gigliotti et al. /13/, focused on the out-of-plane displacements, i.e., curvatures, induced by uniform thermal fields in [0/90] laminated square plates. In Sayman et al. $/ 14 /$, an elastic-plastic thermal stress analysis was carried out on a steel fiber reinforced thermoplastic matrix composite beam. In that study temperature was chosen to vary linearly, that was zero and $T_{0}$ at the upper and lower surfaces, respectively. Shabana and Noda /15/ performed a thermo-elasto-plastic stress analysis in functionally graded materials subjected to thermal loading. They obtained elastic-plastic stresses in a rectangular plate under three kinds of temperature conditions by using finite element technique. Ji-Fan /16/ used a discrete-layer shear deformation laminated plate theory in order to analyze the steady-state thermal stresses in laminated plates. Bektas and Sayman /17/ carried out an analytical elasto-plastic stress analysis on thermoplastic laminated plates. Apalak et al. /18/ carried out a transient thermal analysis of an adhesively bonded and laser-spot welded joint, based on a thermal model developed for the laser-spot welding of multilayered sheets using a pulsed Nd:YAG laser $/ 18 /$.

This paper is concerned with the prediction and examination of the thermal elasto-plastic stress analysis of steel fiber reinforced symmetric thermoplastic composite plates with a circular hole. Finite element method (FEM) was used to compute the thermal stresses under various uniform temperatures loading. In addition thermal residual stress components were calculated, therefore the solution is also carried out in two steps, as thermal elastic stress analysis and thermal elasto-plastic stress analysis.

\section{PROBLEM STATEMENT}

Consider a square composite plate of length $\mathrm{L}=200$ $\mathrm{mm}$, thickness $\mathrm{h}=8 \mathrm{~mm}$ with a hole of diameter $\mathrm{d}=20$ $\mathrm{mm}$ is shown in Figure 1-a. The laminates with symmetric stacking sequences of cross ply $\left[0^{\circ} / 90^{\circ}\right]_{\mathrm{s}}$ and angle ply $\left[30^{\circ} \% 30^{\circ}\right]_{\mathrm{s}},\left[45^{\circ} \%-45^{\circ}\right]_{\mathrm{s}},\left[60^{\circ} /-60^{\circ}\right]_{\mathrm{s}}$ were chosen to investigate and these arrangements are displayed as schematic in Figure 1-b, too. Thermoplastic laminated composite plates were simply supported at all edges.

The distributions of thermal stress components were calculated by FEM, so ANSYS, that is a generalpurpose finite element code, was used for solving the problem. Element type was selected as SHELL 181, which is suitable for analyzing thin to moderately thick shell structures. It is a four-noded element with six degrees of freedom at each node: translations in the $x, y$, and $z$ directions, and rotations about the $\mathrm{x}, \mathrm{y}$, and $\mathrm{z}$-axes. The degenerate triangular option should only be used as filler elements in mesh generation. The geometry, node locations, and the coordinate system for this element are shown in Figure 2. Four nodes define the element: I, J, $\mathrm{K}$, and $\mathrm{L}$. Element formulation is based on logarithmic strain and true stress measures. Element kinematics allow for finite membrane strains (stretching) $/ 19 \%$. In addition, description of stress output for SHELL 181 element type is illustrated in Figure $3 / 19 \%$. 
The schematic finite element model of the composite plate with circular hole is shown in Figure 4. As can be seen in this figure, a mapped mesh shape is chosen for the construction of the model since, compared to a free mesh; a mapped mesh is limited in terms of the element shape it contains and the pattern of the mesh. In addition, when we require this type of mesh, we must construct the geometry as a series of fairly regular volumes /19-20/. Meanwhile, 1453 elements and 1547 nodes modeled the laminated plates, after the mesh process.

Uniform temperature load is applied to the whole of the laminated plate. To investigate the effect of increasing temperature value on thermal stresses, each model was subjected to loading under $60,70,80$ and $90^{\circ} \mathrm{C}$ uniform temperature. In addition, to examine residual stresses, elastic and elasto-plastic solutions were performed for these models.

\subsection{Manufacturing of the Composite Plate}

The composite material was prepared in Dokuz Eylul University, Mechanics Laboratory. The thermoplastic laminated plate consists of high-density polyethylene (HDPE) as a thermoplastic matrix material and steel fibers, as shown in Figure 5 of a preceding study $/ 17 /$. Therefore, it is named steel fiber reinforced thermoplastic laminated composite in the literature. First, polyethylene granules are put into the moulds and the temperature of the electrical heater is increased up to $190^{\circ} \mathrm{C}$. Following this, the material is held for 5 minutes under $2.5 \mathrm{MPa}$ at this temperature value. Then, the temperature of the electrical heater is decreased to $30^{\circ} \mathrm{C}$ under $15 \mathrm{MPa}$ pressure value for 3 minutes and a polyethylene layer is produced. Finally, the steel fibers are put between two thermoplastic layers and processed as the former process. Each layer of fiber-reinforced thermoplastic is of $2 \mathrm{~mm}$ thickness. The final laminated plate is made from four layers so that it has an $8 \mathrm{~mm}$ thickness. The mechanical properties of the plate are shown in Table 1. These mechanical properties are found experimentally. The thermoplastic composite material is assumed to be linearly hardening. In addition, it is assumed that the mechanical properties do not change with increasing temperature.

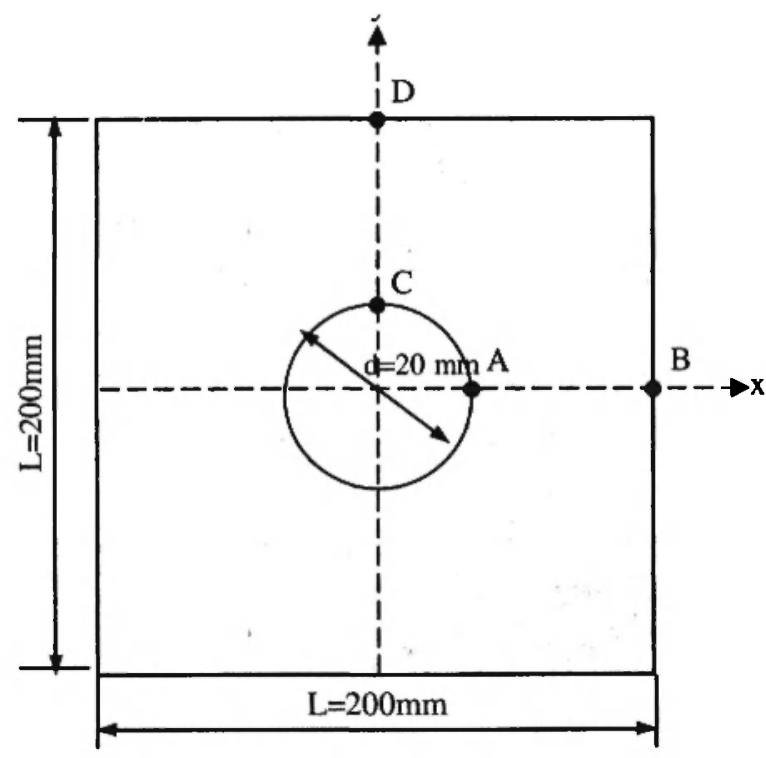

(a)

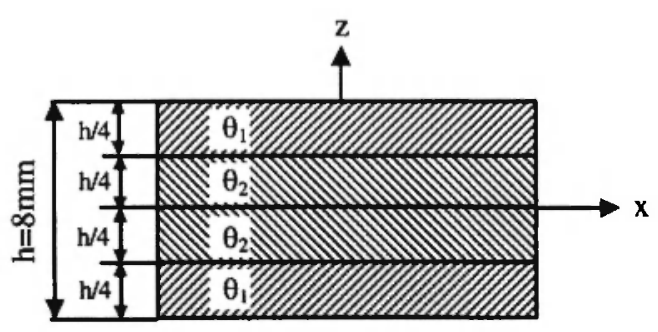

(b)

Fig. 1: a) Geometry of a laminated thermoplastic composite plate with a circular hole

b) Schematic view of symmetric stacking sequence of laminates 
Table 1

Mechanical properties and yield strengths of the composite layer

\begin{tabular}{|c|c|c|c|c|c|c|c|c|c|c|}
\hline \multirow{2}{*}{$\begin{array}{c}E_{1} \\
(\mathrm{MPa})\end{array}$} & \multirow{2}{*}{$\begin{array}{c}\mathrm{E}_{2} \\
(\mathrm{MPa})\end{array}$} & \multirow{2}{*}{$\begin{array}{c}\mathrm{G}_{12} \\
(\mathrm{MPa})\end{array}$} & \multirow{2}{*}{$\begin{array}{c}\mathrm{K} \\
(\mathrm{MPa})\end{array}$} & \multirow{2}{*}{$v_{12}$} & \multirow{2}{*}{$\begin{array}{c}\text { Axial } \\
\text { Strength } \\
\text { X (MPa) }\end{array}$} & \multirow{2}{*}{$\begin{array}{l}\text { Transverse } \\
\text { Strength } \\
\mathrm{Y}(\mathrm{MPa})\end{array}$} & \multirow{2}{*}{$\begin{array}{c}\text { Shear } \\
\text { Strength } \\
\mathrm{S}(\mathrm{MPa})\end{array}$} & \multirow{2}{*}{$\begin{array}{c}\text { Thickness of } \\
\text { each layer } \\
(\mathrm{mm})\end{array}$} & \multicolumn{2}{|c|}{$\begin{array}{l}\text { Thermal expansion } \\
\text { coefficients }\left(1 /{ }^{\circ} \mathrm{C}\right)\end{array}$} \\
\hline & & & & & & & & & $\alpha_{1}$ & $\alpha_{2}$ \\
\hline 41000 & 1200 & 420 & 76 & 0.25 & 39 & 5 & 14 & 2 & 13.1E-06 & $131 \mathrm{E}-06$ \\
\hline
\end{tabular}

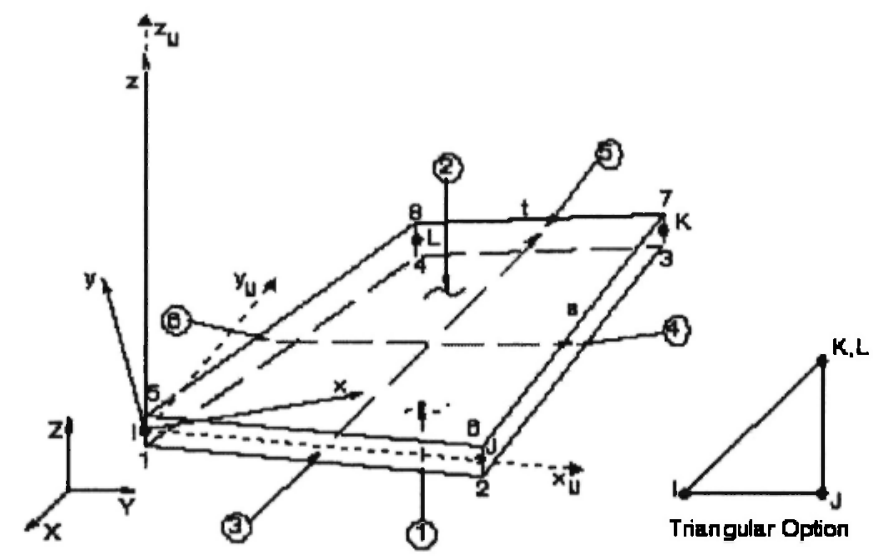

$x_{1 J}=$ Element $x$-axis if ESYS is not supplied.

$x=$ Element $x$-axis if ESYS is supplied.

Fig. 2: The geometry, node locations, and the coordinate system for SHELL 181 element /19/

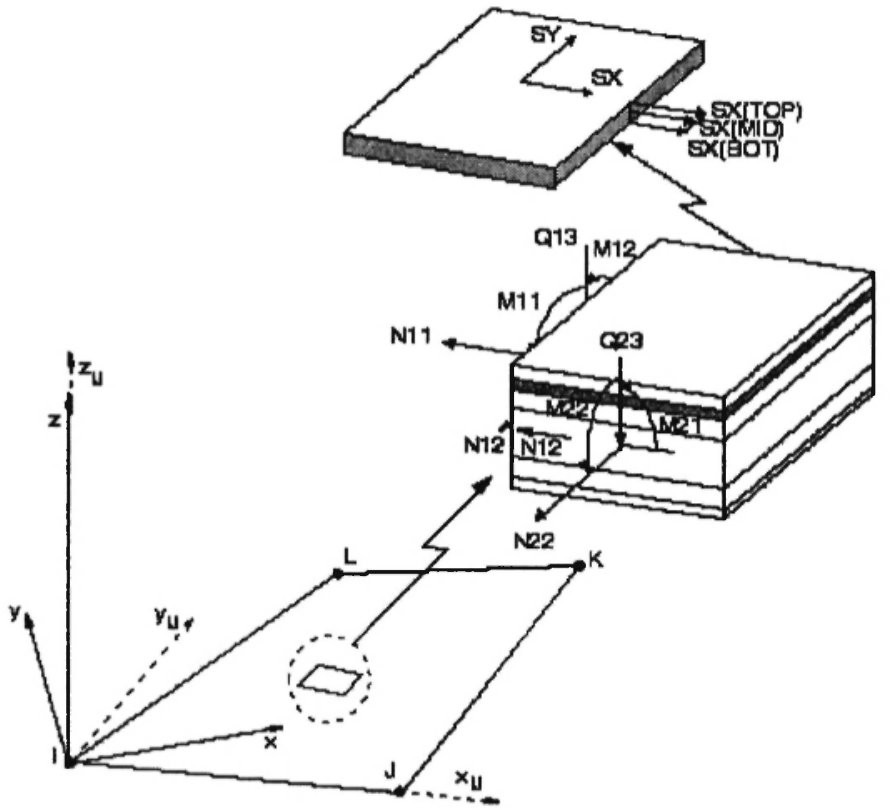

Fig. 3: Description of stress output for SHELL 181 element type /19/ 


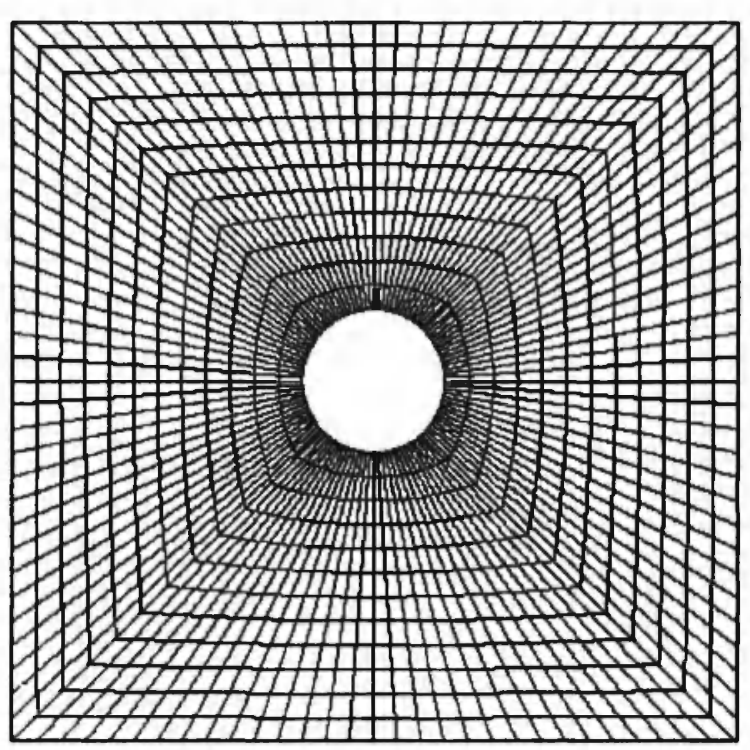

Fig. 4: The schematic finite element model of the composite plate with a circular hole

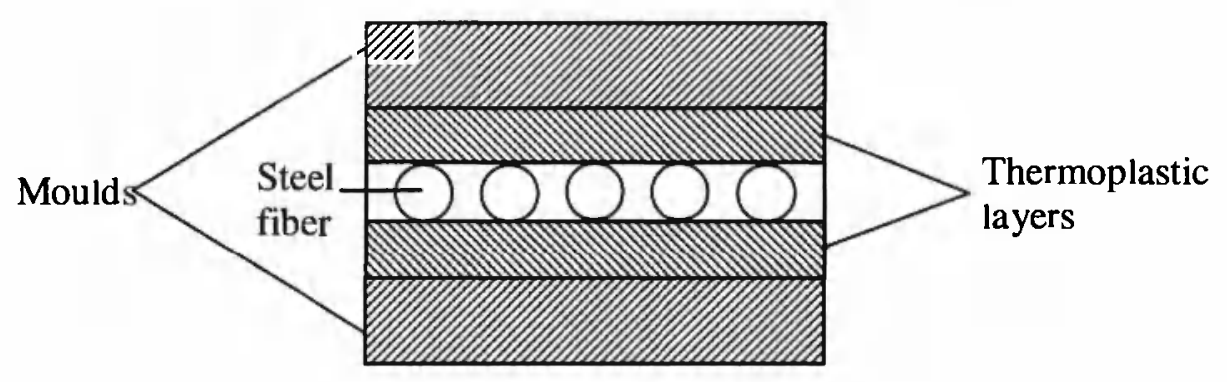

Fig. 5: Manufacturing of the thermoplastic composite material

\subsection{Mathematical Formulation}

The three-dimensional thermoelastic anisotropic strain-stress relations are $/ 3 /$,

$$
\varepsilon_{i}=S_{i j} \sigma_{j}+\alpha_{i} \Delta T \quad i, j=1,2, \ldots ., 6
$$

where the total strains, $\varepsilon_{i}$, are the sum of the mechanical strains, $S_{i j} \sigma_{j}$, and the six free thermal strains, $\alpha_{1} \Delta \mathrm{T}$, for a temperature change $\Delta \mathrm{T}$. The threedimensional stress-strain relations are obtained by inversion:

$$
\sigma_{i}=C_{i j}\left(\varepsilon_{i}-\alpha_{j} \Delta T\right) \quad i, j=1,2, \ldots ., 6
$$

In both equations (1) and (2), the six $\alpha_{i}$ are the coefficients of thermal deformation (expansion or contraction and distortion, i.e., shear), and $\Delta \mathrm{T}$ is the temperature difference. In equation (2), the terms $C_{i j} \alpha_{j} \Delta T$ are the thermal stresses if the total strain is zero $/ 3 /$.

For plane stress on an orthotropic lamina in principal material coordinates,

$$
\left[\begin{array}{c}
\sigma_{1} \\
\sigma_{2} \\
\tau_{12}
\end{array}\right]=\left[\begin{array}{ccc}
\mathrm{Q}_{11} & \mathrm{Q}_{12} & 0 \\
\mathrm{Q}_{12} & \mathrm{Q}_{22} & 0 \\
0 & 0 & \mathrm{Q}_{66}
\end{array}\right]\left[\begin{array}{c}
\varepsilon_{1}-\alpha_{1} \Delta \mathrm{T} \\
\varepsilon_{2}-\alpha_{2} \Delta \mathrm{T} \\
\gamma_{12}
\end{array}\right]
$$

The stresses in laminate coordinates for the $\mathrm{k}^{\text {th }}$ layer are obtained by transformation of coordinates. 


$$
\left[\begin{array}{c}
\sigma_{\mathrm{x}} \\
\sigma_{\mathrm{y}} \\
\tau_{\mathrm{xy}}
\end{array}\right]_{k}=\left[\begin{array}{lll}
\overline{\mathrm{Q}_{11}} & \overline{\mathrm{Q}_{12}} & \overline{\mathrm{Q}_{16}} \\
\overline{\mathrm{Q}_{12}} & \overline{\mathrm{Q}_{22}} & \overline{\mathrm{Q}_{26}} \\
\overline{\mathrm{Q}_{16}} & \overline{\mathrm{Q}_{26}} & \overline{\mathrm{Q}_{66}}
\end{array}\right]\left[\begin{array}{c}
\varepsilon_{\mathrm{x}}-\alpha_{\mathrm{x}} \Delta \mathrm{T} \\
\varepsilon_{\mathrm{y}}-\alpha_{\mathrm{y}} \Delta \mathrm{T} \\
\gamma_{\mathrm{xy}}-\alpha_{\mathrm{xy}} \Delta \mathrm{T}
\end{array}\right]_{k}
$$

The layer stresses are integrated through the thickness; the force resultants are,

$$
\begin{aligned}
& {\left[\begin{array}{c}
\mathrm{N}_{\mathrm{x}} \\
\mathrm{N}_{\mathrm{y}} \\
\mathrm{N}_{\mathrm{xy}}
\end{array}\right]=\left[\begin{array}{lll}
\mathrm{A}_{11} & \mathrm{~A}_{12} & \mathrm{~A}_{16} \\
\mathrm{~A}_{12} & \mathrm{~A}_{22} & \mathrm{~A}_{26} \\
\mathrm{~A}_{16} & \mathrm{~A}_{26} & \mathrm{~A}_{66}
\end{array}\right]\left[\begin{array}{c}
\varepsilon_{\mathrm{x}}^{\mathrm{o}} \\
\varepsilon_{\mathrm{y}}^{\mathrm{o}} \\
\gamma_{\mathrm{xy}}^{0}
\end{array}\right]+} \\
& {\left[\begin{array}{lll}
\mathrm{B}_{11} & \mathrm{~B}_{12} & \mathrm{~B}_{16} \\
\mathrm{~B}_{12} & \mathrm{~B}_{22} & \mathrm{~B}_{26} \\
\mathrm{~B}_{16} & \mathrm{~B}_{26} & \mathrm{~B}_{66}
\end{array}\right]\left[\begin{array}{c}
\mathrm{K}_{\mathrm{x}} \\
\mathrm{K}_{\mathrm{y}} \\
\mathrm{K}_{\mathrm{xy}}
\end{array}\right]-\left[\begin{array}{c}
\mathrm{N}_{\mathrm{x}}^{\mathrm{T}} \\
\mathrm{N}_{\mathrm{y}}^{\mathrm{T}} \\
\mathrm{N}_{\mathrm{xy}}^{\mathrm{T}}
\end{array}\right]}
\end{aligned}
$$

in which the $A_{i j}$ and $B_{i j}$ are the usual extensional and bending-extension coupling stiffnesses and the thermal forces are

$$
\left[\begin{array}{c}
N_{x}^{T} \\
N_{y}^{T} \\
N_{x y}^{T}
\end{array}\right]=\int\left[\begin{array}{lll}
\overline{Q_{11}} & \overline{Q_{12}} & \overline{Q_{16}} \\
\overline{Q_{12}} & \overline{Q_{22}} & \overline{Q_{26}} \\
\overline{Q_{26}} & \overline{Q_{66}}
\end{array}\right]_{k}\left[\begin{array}{c}
\alpha_{x} \\
\alpha_{y} \\
\alpha_{x y}
\end{array}\right]_{k} \Delta \mathrm{Tdz}
$$

In a similar manner, the moment resultants are obtained by integrating the moment of the stresses through the thickness $/ 3 /$ :

$$
\begin{aligned}
& {\left[\begin{array}{c}
M_{x} \\
M_{y} \\
M_{x y}
\end{array}\right]=\left[\begin{array}{lll}
B_{11} & B_{12} & B_{16} \\
B_{12} & B_{22} & B_{26} \\
B_{16} & B_{26} & B_{66}
\end{array}\right]\left[\begin{array}{c}
\varepsilon_{x}^{o} \\
\varepsilon_{y}^{o} \\
\gamma_{x y}^{o}
\end{array}\right]+} \\
& {\left[\begin{array}{lll}
D_{11} & D_{12} & D_{16} \\
D_{12} & D_{22} & D_{26} \\
D_{16} & D_{26} & D_{66}
\end{array}\right]\left[\begin{array}{c}
K_{x} \\
K_{y} \\
K_{x y}
\end{array}\right]-\left[\begin{array}{l}
M_{x}^{T} \\
M_{y}^{T} \\
M_{x y}^{T}
\end{array}\right]}
\end{aligned}
$$

in which the $D_{i j}$ are the usual bending stiffnesses and the thermal moments are,

$$
\left[\begin{array}{c}
M_{x}^{T} \\
M_{y}^{T} \\
M_{x y}^{T}
\end{array}\right]=\int\left[\begin{array}{lll}
\overline{Q_{11}} & \overline{Q_{12}} & \overline{Q_{16}} \\
\overline{Q_{12}} & \overline{Q_{22}} & \overline{Q_{26}} \\
\overline{Q_{16}} & \overline{Q_{26}} & \overline{Q_{66}}
\end{array}\right]_{k}\left[\begin{array}{c}
\alpha_{x} \\
\alpha_{y} \\
\alpha_{x y}
\end{array}\right]_{k} \Delta \mathrm{Tdz}
$$

Actually, only in the restricted case of perfect constraint are the $\mathrm{N}^{\mathrm{T}}$ and $\mathrm{M}^{\mathrm{T}}$ thermal forces and moments, respectively. However, the force and moment resultants can be rearranged to read,

$$
\begin{aligned}
& {\left[\begin{array}{l}
\overline{N_{x}} \\
\overline{N_{y}} \\
N_{x y}
\end{array}\right]=\left[\begin{array}{c}
N_{x}+N_{x}^{T} \\
N_{y}+N_{y}^{T} \\
N_{x y}+N_{x y}^{T}
\end{array}\right]=} \\
& {\left[\begin{array}{lll}
A_{11} & A_{12} & A_{16} \\
A_{12} & A_{22} & A_{26} \\
A_{16} & A_{26} & A_{66}
\end{array}\right]\left[\begin{array}{c}
\varepsilon_{x}^{0} \\
\varepsilon_{y}^{0} \\
\gamma_{x y}^{0}
\end{array}\right]+} \\
& {\left[\begin{array}{lll}
B_{11} & B_{12} & B_{16} \\
B_{12} & B_{22} & B_{26} \\
B_{16} & B_{26} & B_{66}
\end{array}\right]\left[\begin{array}{c}
K_{x} \\
K_{y} \\
K_{x y}
\end{array}\right]}
\end{aligned}
$$

$$
\left[\begin{array}{l}
\overline{M_{x}} \\
\overline{M_{y}} \\
\overline{M_{x y}}
\end{array}\right]=\left[\begin{array}{c}
M_{x}+M_{x}^{T} \\
M_{y}+M_{y}^{T} \\
M_{x y}+M_{x y}^{T}
\end{array}\right]=
$$

$$
\begin{aligned}
& {\left[\begin{array}{lll}
\mathrm{B}_{11} & \mathrm{~B}_{12} & \mathrm{~B}_{16} \\
\mathrm{~B}_{12} & \mathrm{~B}_{22} & \mathrm{~B}_{26} \\
\mathrm{~B}_{16} & \mathrm{~B}_{26} & \mathrm{~B}_{66}
\end{array}\right]\left[\begin{array}{l}
\varepsilon_{\mathrm{x}}^{0} \\
\varepsilon_{\mathrm{y}}^{\mathrm{v}} \\
r_{\mathrm{xy}}^{0}
\end{array}\right]+} \\
& {\left[\begin{array}{lll}
\mathrm{D}_{11} & \mathrm{D}_{12} & \mathrm{D}_{16} \\
\mathrm{D}_{12} & \mathrm{D}_{22} & \mathrm{D}_{26} \\
\mathrm{D}_{16} & \mathrm{D}_{26} & \mathrm{D}_{66}
\end{array}\right]\left[\begin{array}{l}
\mathrm{K}_{\mathrm{x}} \\
\mathrm{K}_{\mathrm{y}} \\
\mathrm{K}_{\mathrm{xy}}
\end{array}\right]}
\end{aligned}
$$

In the form of equations (9) and (10), the thermal portion of thermal and mechanical stress problems can be treated as equivalent mechanical loads defined by $\mathrm{N}^{\mathrm{T}}$ and $\mathrm{M}^{\mathrm{T}}$ in Equations (6) and (8), respectively in addition to the mechanical loads, $N$ and $M / 3 /$.

The temperature causing yielding of the layers can be found by using the stress components. The stress components in the principal material directions are 
written as,

$$
\left\{\begin{array}{c}
\sigma_{1} \\
\sigma_{2} \\
\tau_{12}
\end{array}\right\}=\left[\begin{array}{ccc}
\cos ^{2} & \sin ^{2} & 2 \sin \cos \\
\sin ^{2} & \cos ^{2} & -2 \sin \cos \\
-\sin \cos & \sin \cos & \cos ^{2}-\sin ^{2}
\end{array}\right]\left\{\begin{array}{c}
\sigma_{x} \\
\sigma_{y} \\
\tau_{x y}
\end{array}\right\}
$$

These principal stresses are substituted into the TsaiHill criterion in order to find the temperature, which is causing yielding of a lamina $/ 3 /$.

The elasto-plastic solution is performed for small plastic deformations. The Tsai-Hill theory is used as a yield criterion because of the same yield points in tension and compression for fiber reinforced thermoplastic composite layers. The criterion can be written below as $/ 3 /$,

$$
\frac{\sigma_{1}^{2}}{\mathrm{X}^{2}}+\frac{\sigma_{2}^{2}}{\mathrm{Y}^{2}}-\left(\frac{1}{\mathrm{X}^{2}}+\frac{1}{\mathrm{Y}^{2}}-\frac{1}{\mathrm{Z}^{2}}\right) \sigma_{1} \sigma_{2}+\frac{\tau_{12}^{2}}{\mathrm{~S}^{2}}-1
$$

Multiplying Eq.(12) by $\mathrm{X}^{\hat{\alpha}}$ gives us in the first principal material direction as,

$\bar{\sigma}_{\mathrm{eq}}=$
$\bar{\sigma}=\sqrt{\sigma_{1}{ }^{2}-\mathrm{X}^{2}\left(\frac{1}{\mathrm{X}^{2}}+\frac{1}{\mathrm{Y}^{2}}-\frac{1}{\mathrm{Z}^{2}}\right) \sigma_{1} \sigma_{2}+\frac{\sigma_{2}{ }^{2} \mathrm{X}^{2}}{\mathrm{Y}^{2}}+\frac{\tau_{12}{ }^{2} \mathrm{X}^{2}}{\mathrm{~S}^{2}}}$

The yield strengths of the lamina in the second and third principal material directions are the same, owing to the same alignment of the fibers in these directions, so that Eq. 13 can be written as,

$$
\bar{\sigma}^{2}=\bar{v}_{1}^{2}-\bar{v}_{1} \bar{v}_{2}+\frac{\sigma_{2}{ }^{2} X^{2}}{Y^{2}}+\frac{\tau_{12}{ }^{2} X^{2}}{S^{2}}
$$

where $\bar{\sigma}$ (equivalent stresss) is given by Ludwik's equation as,

$$
\bar{\sigma}=\sigma_{0}+K \varepsilon_{p}
$$

To calculate the residual stresses it is necessary to superpose on the thermal stress system. The superposition of the elastic stresses and plastic stresses provides the residual stress values as,

$$
\begin{aligned}
& \left(\sigma_{x}\right)_{r}=\left(\sigma_{x}\right)_{p}-\left(\sigma_{x}\right)_{e} \\
& \left(\sigma_{y}\right)_{r}=\left(\sigma_{y}\right)_{p}-\left(\sigma_{y}\right)_{e} \\
& \left(\tau_{x y}\right)_{r}=\left(\tau_{x y}\right)_{p}-\left(\tau_{x y}\right)_{e}
\end{aligned}
$$

For this purpose, the solution was performed in two phases using the finite element method by ANSYS program. Firstly, elastic solution was applied on the thermoplastic composite plate. Then elasto-plastic solution was applied on it. Finally, residual stresses were obtained using Eq. 16.

\section{RESULTS AND DISCUSSION}

In this investigation, a thermal elastic, elasto-plastic and residual stress analysis of symmetric steel fiber reinforced thermoplastic laminated composite plates with a central circular hole, under different uniform temperature loadings, have been calculated using finite element analysis. The width plate-to-the hole diameter, $\mathrm{L} / \mathrm{D}$, ratio was selected as 10 . The laminated composite plates are assumed to be simple supported. Temperature values were chosen as $60,70,80$ and $90^{\circ} \mathrm{C}$ and temperature loadings were uniform. The symmetric laminated composite plates with a circular hole diameters were composed of four orthotropic layers oriented with cross-ply, $\left[0^{\circ} / 90^{\circ}\right]_{s}$, and angle ply, $\left[30^{\circ} \%\right.$ $\left.30^{\circ}\right]_{s},\left[45^{\circ} /-45^{\circ}\right]_{s}$, $\left[60^{\circ} /-60^{\circ}\right]_{s}$ in a symmetrical manner.

The magnitude of thermal stress components at the upper and lower surfaces of symmetric plates were the same for all uniform temperature loading, therefore they are presented in the tables only for upper surfaces.

The thermal elastić, elassto-plastic, residual stress components, and equivalent plastic strain depending on applied uniform temperature for $\mathrm{x}$ and $\mathrm{y}$ direction $\left(\sigma_{\mathrm{x}}\right.$, $\sigma_{y}$ and $\tau_{x y}$ ) for symmetric cross-ply, $\left[0^{\circ} / 90^{\circ}\right]_{s}$ and angle ply, $\left[30^{\circ} \%-30^{\circ}\right]_{\mathrm{s}},\left[45^{\circ} \%-45^{\circ}\right]_{\mathrm{s}},\left[60^{\circ} \% 60^{\circ}\right]_{\mathrm{s}}$ laminated plate (Nodes A, B, C and D) with a circular hole are shown in Tables 2 and 3, respectively. It can be seen from these tables that the magnitude of the thermal elastic, elastoplastic stresses and equivalent plastic strain increases related to rise of uniform temperature values, so the 
highest values of thermal stress components and equivalent plastic strain are obtained for $90^{\circ} \mathrm{C}$ uniform temperature loading.

Meanwhile, for all uniform temperatures; the absolute values of stress components $\sigma_{x}$ and $\sigma_{y}$ are the same for cross ply $\left[0^{\circ} / 90^{\circ}\right]_{s}$ laminated plates in Table 2 . This situation similar for angle ply $\left[45^{\circ} /-45^{\circ}\right]_{s}$ laminated plates in Table 3. However, the absolute values of thermal stress components for $\mathrm{x}$ and $\mathrm{y}$ directions show completely different values from each other for angle ply $\left[30^{\circ} /-30^{\circ}\right]_{\mathrm{s}}$, and $\left[60^{\circ} /-60^{\circ}\right]_{\mathrm{s}}$ laminated plates.

Maximum values of tensile elastic and elasto-plastic stresses depending on applied uniform temperature for symmetric cross-ply and angle-ply laminated plate with a circular hole are shown in Table 4, and maximum values of compressive elastic and elasto-plastic stresses depending on applied uniform temperature for symmetric cross-ply and angle-ply laminated plate with a circular hole are illustrated in Table 5. As seen in these tables, absolute thermal stress values increase depending on increasing of applied uniform temperature loadings. Moreover, maximum tensile stress and maximum compressive stress values are calculated on angle-ply $\left[60^{\circ} /-60^{\circ}\right]_{\mathrm{s}}$ laminated plate while minimum tensile stress and minimum compressive stress values are obtained on angle-ply $\left[45^{\circ} /-45^{\circ}\right]_{s}$ laminated plate. It is known that a composite structure can be damaged influence of uniform temperature any point or zone, for this reason Table 4 and 5 are given a thought related to failure of laminated thermoplastic composite structure.

Table 2

Elastic, elasto-plastic, residual stress components, and equivalent plastic strain for symmetric cross $/ \mathrm{ply}\left[0^{\circ} / 90^{\circ}\right]_{\mathrm{s}}$ laminated plate with a circular hole

\begin{tabular}{|c|c|c|c|c|c|c|c|c|c|c|c|}
\hline $\begin{array}{c}\mathrm{T} \\
\left({ }^{\circ} \mathrm{C}\right)\end{array}$ & Node & $\begin{array}{c}\left(\sigma_{\mathrm{x}}\right)_{\mathrm{p}} \\
(\mathrm{MPa})\end{array}$ & $\begin{array}{c}\left(\sigma_{y}\right)_{p} \\
(\mathrm{MPa})\end{array}$ & $\begin{array}{c}\left(\tau_{x y}\right)_{p} \\
(\mathrm{MPa})\end{array}$ & $\begin{array}{c}\left(\sigma_{\mathrm{x}}\right)_{\mathrm{e}} \\
(\mathrm{MPa})\end{array}$ & $\begin{array}{c}\left(\sigma_{y}\right)_{e} \\
(\mathrm{MPa})\end{array}$ & $\begin{array}{c}\left(\tau_{x y}\right)_{e} \\
(\mathrm{MPa})\end{array}$ & $\begin{array}{c}\left(\sigma_{\mathrm{x}}\right)_{\mathrm{r}} \\
(\mathrm{MPa})\end{array}$ & $\begin{array}{c}\left(\sigma_{y}\right)_{r} \\
(\mathrm{MPa})\end{array}$ & $\begin{array}{c}\left(\tau_{x y}\right)_{r} \\
(\mathrm{MPa})\end{array}$ & $\begin{array}{c}\varepsilon_{\mathrm{p}} \\
\left(10^{-6}\right)\end{array}$ \\
\hline \multirow{4}{*}{60} & A & 4.670 & -4.670 & 0.896 & 7.694 & -7.694 & 1.477 & -3.024 & 3.024 & -0.581 & 349 \\
\hline & B & 4.915 & -4.915 & -0.168 & 8.097 & -8.097 & -0.480 & -3.182 & 3.182 & 0.312 & 349 \\
\hline & C & -4.542 & 4.542 & -1.504 & -7.483 & 7.483 & -2.478 & 2.941 & -2.941 & 0.974 & 349 \\
\hline & D & -4.915 & 4.915 & 0.261 & -8.097 & 8.097 & -0.556 & 3.182 & -3.182 & 0.817 & 349 \\
\hline \multirow{4}{*}{$? ?$ ?n } & A & 4.672 & -4.672 & 0.897 & 8.976 & -8.976 & 1.723 & -4.304 & 4.304 & -0.826 & 496 \\
\hline & B & 4.916 & -4.916 & 0.952 & 9.446 & -9.446 & $=0.539$ & -4.53 & 4.53 & 1.491 & 496 \\
\hline & C & -4.543 & 4.543 & -1.505 & -8.730 & 8.730 & -2.891 & 4.187 & -4.187 & 1.386 & 496 \\
\hline & D & -4.916 & 4.916 & -0.521 & -9.446 & 9.446 & -0.685 & 4.53 & -4.53 & 0.164 & 496 \\
\hline \multirow{4}{*}{$\stackrel{8}{8}$} & A & 4.673 & -4.673 & 0.897 & 10.259 & -10.259 & 1.969 & -5.586 & 5.586 & -1.072 & 644 \\
\hline & B & 4.918 & -4.918 & -0.157 & 10.796 & -10.796 & -0.681 & -5.878 & 5.878 & 0.524 & 644 \\
\hline & $\mathrm{C}$ & -5.545 & 4.545 & -1.505 & -9.997 & 9.997 & -3.304 & 4.452 & -5.452 & 1.799 & 644 \\
\hline & D & -4.918 & 4.918 & 0.186 & -10.796 & 10.796 & -0.117 & 5.878 & -5.878 & 0.303 & 644 \\
\hline \multirow{4}{*}{ an } & A & 4.674 & -4.674 & 0.897 & 11.541 & -11.541 & 2.216 & -6.867 & 6.867 & -1.319 & 792 \\
\hline & B & 4.919 & -4.919 & -0.919 & 12.146 & -12.146 & -0.746 & -7.227 & 7.227 & -0.173 & 792 \\
\hline & C & -4.546 & 4.546 & 1.468 & -11.225 & 11.225 & -3.717 & 6.679 & -6.679 & 5.185 & 792 \\
\hline & D & -4.919 & 4.919 & 0.624 & -12.146 & 12.146 & -0.123 & 7.227 & -7.227 & 0.747 & 792 \\
\hline
\end{tabular}


Table 3

Elastic, elasto-plastic, residual stress components, and equivalent plastic strain for symmetric angle $/ \mathrm{ply}\left[30^{\circ} /-30^{\circ}\right]$, $\left[45^{\circ} /-45^{\circ}\right]_{s},\left[60^{\circ} \%-60^{\circ}\right]_{s}$, laminated plate with a circular hole

\begin{tabular}{|c|c|c|c|c|c|c|c|c|c|c|c|c|}
\hline$\theta$ & $\begin{array}{c}\mathrm{T} \\
\left({ }^{\circ} \mathrm{C}\right) \\
\end{array}$ & Node & $\begin{array}{c}\left(\sigma_{\mathrm{x}}\right)_{\mathrm{p}} \\
(\mathrm{MPa})\end{array}$ & $\begin{array}{c}\left(\sigma_{y}\right)_{\mathrm{p}} \\
(\mathrm{MPa})\end{array}$ & $\begin{array}{c}\left(\tau_{x y}\right)_{p} \\
(\mathrm{MPa})\end{array}$ & $\begin{array}{c}\left(\sigma_{\mathrm{x}}\right)_{\mathrm{e}} \\
(\mathrm{MPa})\end{array}$ & $\begin{array}{c}\left(\sigma_{y}\right)_{e} \\
(\mathrm{MPa})\end{array}$ & $\begin{array}{c}\left(\tau_{\mathrm{xy}}\right)_{\mathrm{e}} \\
(\mathrm{MPa})\end{array}$ & $\begin{array}{c}\left(\sigma_{\mathbf{x}}\right)_{\mathrm{r}} \\
(\mathrm{MPa})\end{array}$ & $\begin{array}{c}\left(\sigma_{y}\right)_{r} \\
(\mathrm{MPa})\end{array}$ & $\begin{array}{c}\left(\tau_{x y}\right)_{r} \\
(\mathrm{MPa})\end{array}$ & $\begin{array}{c}\varepsilon_{\mathrm{p}} \\
\left(10^{-6}\right) \\
\end{array}$ \\
\hline \multirow{16}{*}{$\begin{array}{l}\overrightarrow{0} \\
\dot{0} \\
\dot{0} \\
\dot{0}\end{array}$} & \multirow{4}{*}{60} & A & -0.326 & 4.681 & 4.107 & -0.177 & 4.842 & 5.030 & -0.149 & -0.161 & -0.923 & 0 \\
\hline & & B & 0.099 & -2.115 & 3.881 & 0.104 & -3.538 & 4.891 & -0.005 & 1.423 & -1.010 & 184 \\
\hline & & C & 5.921 & -1.289 & -4.804 & 5.865 & -0.618 & -4.824 & 0.056 & -0.671 & 0.020 & 0 \\
\hline & & D & -2.094 & -0.219 & -3.762 & -3.706 & -0.434 & -4.559 & 1.612 & 0.215 & 0.797 & 170 \\
\hline & \multirow{4}{*}{70} & A & -0.331 & 4.689 & 4.222 & -0.206 & 5.649 & 5.868 & -0.125 & -0.96 & -1.646 & 0 \\
\hline & & B & 0.102 & -2.117 & 3.884 & 0.121 & -4.127 & 5.706 & -0.019 & 2.010 & -1.822 & 325 \\
\hline & & $\mathrm{C}$ & 5.927 & -0.948 & -5.555 & 6.843 & -0.721 & -5.628 & -0.916 & -0.227 & 0.073 & 0 \\
\hline & & D & -2.116 & -0.225 & -3.781 & -4.323 & -0.506 & -5.319 & 2.207 & 0.281 & 1.538 & 305 \\
\hline & \multirow{4}{*}{80} & A & -0.373 & 4.777 & 4.765 & -0.236 & 6.456 & 6.706 & -0.137 & -1.679 & -1.941 & 0 \\
\hline & & B & 0.105 & -2.118 & 3.886 & 0.138 & -4.717 & 6.521 & -0.033 & 2.599 & -2.635 & 468 \\
\hline & & $\mathrm{C}$ & 5.977 & -1.290 & -6.296 & 7.820 & -0.824 & -6.433 & -1.843 & -0.466 & 0.137 & 0 \\
\hline & & $\mathrm{D}$ & -2.126 & -0.227 & -3.795 & -4.941 & -0.579 & -6.079 & 2.815 & 0.352 & 2.284 & 445 \\
\hline & \multirow{4}{*}{90} & A & -0.376 & 4.881 & 5.107 & -0.266 & 7.263 & 7.545 & -0.110 & -2.382 & -2.438 & 84 \\
\hline & & B & 0.199 & -2.225 & 3.889 & 0.156 & -5.306 & 7.337 & 0.043 & 3.081 & -3.448 & 611 \\
\hline & & $\mathrm{C}$ & 5.981 & -1.298 & -6.804 & 8.798 & -0.927 & -7.237 & -2.817 & -0.371 & 0.433 & 66 \\
\hline & & $\mathrm{D}$ & -2.194 & -0.229 & -3.802 & -5.559 & -0.651 & -6.839 & 3.365 & 0.422 & 3.037 & 587 \\
\hline \multirow{16}{*}{$\begin{array}{l}\frac{a}{n} \\
\frac{n}{i} \\
\dot{i n}\end{array}$} & \multirow{4}{*}{60} & $\mathrm{~A}$ & -0.896 & 0.896 & 4.670 & -1.477 & 1.477 & 7.694 & 0.581 & -0.581 & -3.024 & 349 \\
\hline & & B & 0.664 & -0.664 & 4.915 & 0.169 & 0.452 & 8.097 & 0.495 & -1.116 & -3.182 & 349 \\
\hline & & $\mathrm{C}$ & 1.504 & -1.504 & -4.542 & 2.478 & -2.478 & -7.483 & -0.974 & 0.974 & 2.941 & 349 \\
\hline & & $\mathrm{D}$ & 0.664 & 0.664 & -4.915 & -0.413 & 0.454 & -8.097 & 1.077 & 0.21 & 3.182 & 349 \\
\hline & \multirow{4}{*}{70} & A & -0.897 & 0.897 & 4.672 & -1.723 & 1.723 & 8.976 & 0.826 & -0.826 & -4.304 & 496 \\
\hline & & B & 0.804 & -0.804 & 4.916 & 0.612 & -0.861 & 9.446 & 0.192 & 0.057 & -4.530 & 496 \\
\hline & & $\mathrm{C}$ & 1.505 & -1.505 & -4.543 & 2.891 & -2.891 & -8.730 & -1.386 & 1.386 & 4.187 & 496 \\
\hline & & $\mathrm{D}$ & 0.804 & 0.804 & -4.916 & -0.490 & -0.595 & -9.446 & 1.294 & 1.399 & 4.530 & 496 \\
\hline & \multirow{4}{*}{80} & A & -0.898 & 0.898 & 4.674 & -1.969 & 1.969 & 10.259 & 1.071 & -1.071 & -5.585 & 644 \\
\hline & & B & 0.855 & -0.855 & 4.918 & 0.639 & 0.864 & 10.796 & 0.216 & -1.719 & -5.878 & 644 \\
\hline & & $\mathrm{C}$ & 1.506 & -1.506 & -4.544 & 3.304 & -3.304 & -9.977 & -1.798 & 1.798 & 5.433 & 644 \\
\hline & & D & 0.805 & 0.805 & -4.917 & -0.639 & -0.821 & -10.796 & 1.444 & 1.626 & 5.879 & 644 \\
\hline & \multirow{4}{*}{90} & $\mathrm{~A}$ & -0.899 & 0.899 & 4.675 & -2.216 & 2.216 & 11.541 & 1.317 & -1.317 & -6.866 & 792 \\
\hline & & B & 0.906 & -0.906 & 4.932 & 0.666 & 0.985 & 12.146 & 0.240 & -1.891 & -7.214 & 792 \\
\hline & & $\mathrm{C}$ & 1.507 & -1.507 & -4.535 & 3.717 & -3.717 & -11.225 & -2.210 & 2.210 & 6.690 & 792 \\
\hline & & D & 0.806 & 0.806 & -4.918 & -0.706 & -0.829 & -12.146 & 1.512 & 1.635 & 7.228 & 792 \\
\hline \multirow{4}{*}{$\begin{array}{l}0 \\
0 \\
8 \\
0 \\
0 \\
0 \\
0\end{array}$} & \multirow{4}{*}{60} & $\mathrm{~A}$ & -1.275 & -9.966 & 1.656 & -1.540 & -15.622 & -1.837 & 0.265 & 5.656 & 3.493 & 0 \\
\hline & & B & -0.019 & 8.156 & 7.667 & -0.200 & 12.966 & 11.922 & 0.181 & -4.810 & -4.255 & 312 \\
\hline & & $\mathrm{C}$ & -14.289 & -2.011 & -0.410 & -23.215 & -2.047 & 3.667 & 8.926 & 0.036 & -4.077 & 0 \\
\hline & & D & 8.193 & 0.025 & -7.660 & 12.679 & 0.035 & -11.779 & -4.486 & -0.010 & 4.119 & 298 \\
\hline
\end{tabular}


Table 3 (continued)

\begin{tabular}{|c|c|c|c|c|c|c|c|c|c|c|c|}
\hline \multirow{4}{*}{70} & $\mathrm{~A}$ & -1.412 & -9.977 & 1.670 & -1.797 & -17.225 & -2.143 & 0.385 & 7.248 & 3.813 & 0 \\
\hline & B & -0.021 & 8.210 & 7.679 & -0.023 & 15.127 & 13.909 & 0.002 & -6.917 & -6.23 & 458 \\
\hline & $\mathrm{C}$ & -14.913 & -2.380 & -0.455 & -27.085 & -2.388 & 4.278 & 12.172 & 0.008 & -4.733 & 0 \\
\hline & D & 8.212 & 0.026 & -7.675 & 14.792 & 0.039 & -13.742 & -6.58 & -0.013 & 6.067 & 443 \\
\hline \multirow{4}{*}{80} & A & -1.597 & -10.190 & 1.679 & -2.054 & -20.829 & -2.450 & 0.457 & 10.639 & 4.129 & 336 \\
\hline & B & -0.026 & 8.266 & 7.691 & -0.028 & 17.288 & 15.896 & 0.002 & -9.022 & -8.205 & 604 \\
\hline & $\mathrm{C}$ & -14.675 & -2.534 & 0.465 & -30.954 & -2.729 & 4.889 & 16.279 & 0.195 & -4.424 & 399 \\
\hline & D & 8.236 & 0.027 & -7.692 & 16.905 & 0.044 & -15.705 & -8.669 & -0.017 & 8.013 & 587 \\
\hline \multirow{4}{*}{ مֵֵ } & A & -1.620 & -10.583 & 0.213 & -2.311 & -23.433 & -2.756 & 0.691 & 12.850 & 2.969 & 382 \\
\hline & B & -0.028 & 8.324 & 7.705 & -0.030 & 19.448 & 17.883 & 0.002 & -11.124 & -10.178 & 750 \\
\hline & $\mathrm{C}$ & -14.747 & -2.784 & 0.952 & -34.823 & -3.070 & 5.501 & 20.076 & 0.286 & -4.549 & 441 \\
\hline & D & 8.241 & 0.028 & -7.711 & 19.018 & 0.050 & -17.668 & -10.777 & -0.022 & 9.957 & 732 \\
\hline
\end{tabular}

Table 4

Maximum values of tensile elastic and elasto-plastic stresses for symmetric cross $/ \mathrm{ply}\left[0^{\circ} / 90^{\circ}\right]_{\mathrm{s}}$ and angle/ply $\left[30^{\circ} /-30^{\circ}\right]$, $\left[45^{\circ} /-45^{\circ}\right]_{\mathrm{s}}$ and $\left[60^{\circ} \%-60^{\circ}\right]_{\mathrm{s}}$ laminated plates with a circular hole

\begin{tabular}{|c|c|c|c|c|c|c|c|}
\hline$\theta$ & $\begin{array}{c}\mathrm{T} \\
\left({ }^{\circ} \mathrm{C}\right)\end{array}$ & $\begin{array}{c}\left(\sigma_{\mathrm{x}}\right)_{\mathrm{p}} \\
(\mathrm{MPa})\end{array}$ & $\begin{array}{c}\left(\sigma_{y}\right)_{p} \\
(\mathrm{MPa})\end{array}$ & $\begin{array}{c}\left(\tau_{x y}\right)_{p} \\
(\mathrm{MPa})\end{array}$ & $\begin{array}{c}\left(\sigma_{\mathrm{x}}\right)_{\mathrm{e}} \\
(\mathrm{MPa})\end{array}$ & $\begin{array}{c}\left(\sigma_{v}\right)_{e} \\
(\mathrm{MPa})\end{array}$ & $\begin{array}{c}\left(\tau_{x y}\right)_{e} \\
(\mathrm{MPa})\end{array}$ \\
\hline \multirow{4}{*}[0^{\circ}/90^{\circ}]{$_{\mathrm{s}}$} & 60 & 4.916 & 4.916 & 4.782 & 8.097 & 8.097 & 7.878 \\
\hline & 70 & 4.917 & 4.917 & 4.784 & 9.447 & 9.447 & 9.191 \\
\hline & 80 & 4.918 & 4.918 & 4.785 & 10.796 & 10.796 & 10.504 \\
\hline & 90 & 4.920 & 4.920 & 4.787 & 12.146 & 12.146 & 11.817 \\
\hline \multirow{4}{*}[30^{\circ}/-30^{\circ}]{$_{s}$} & 60 & 16.323 & 23.667 & 12.153 & 29.603 & 44.106 & 20.597 \\
\hline & 70 & 16.635 & 23.952 & 12.291 & 34.536 & 51.457 & 24.030 \\
\hline & 80 & 16.875 & 24.195 & 12.475 & 39.470 & 58.808 & 27.462 \\
\hline & 90 & 16.889 & 24.370 & 12.590 & 44.404 & 66.159 & 30.895 \\
\hline \multirow{4}{*}[45^{\circ}/-45^{\circ}]{$_{\mathrm{s}}$} & 60 & 4.809 & 4.782 & 4.916 & 7.922 & 7.878 & 8.097 \\
\hline & 70 & 4.811 & 4.784 & 4.917 & 9.243 & 9.191 & 9.447 \\
\hline & 80 & 4.812 & 4.785 & 4.918 & 10.563 & 10.504 & 10.796 \\
\hline & 90 & 4.814 & 4.787 & 4.920 & 11.884 & 11.817 & 12.146 \\
\hline \multirow{4}{*}[60^{\circ}/-60^{\circ}]{$_{\mathrm{s}}$} & 60 & 22.454 & 9.289 & 9.191 & 40.418 & 20.324 & 15.270 \\
\hline & 70 & 22.908 & 9.682 & 9.273 & 47.154 & 23.711 & 17.815 \\
\hline & 80 & 23.293 & 10.296 & 9.366 & 53.890 & 27.099 & 20.360 \\
\hline & 90 & 23.699 & 10.479 & 9.805 & 60.627 & 30.486 & 30.486 \\
\hline
\end{tabular}


Table 5

Maximum values of compressive elastic and elasto-plastic stresses for symmetric cross/ply $\left[0^{\circ} / 90^{\circ}\right]_{\mathrm{s}}$ and angle/ply $\left[30^{\circ} \%\right.$ $\left.30^{\circ}\right]_{\mathrm{s}},\left[45^{\circ} /-45^{\circ}\right]_{\mathrm{s}}$ and $\left[60^{\circ} /-60^{\circ}\right]_{\mathrm{s}}$ laminated plates with a circular hole

\begin{tabular}{|c|c|ccc|ccc|}
\hline \multirow{3}{*}{$A$} & $\begin{array}{c}\mathrm{T} \\
\left({ }^{\circ} \mathrm{C}\right)\end{array}$ & $\begin{array}{c}\left(\sigma_{\mathrm{x}}\right)_{\mathrm{p}} \\
(\mathrm{MPa})\end{array}$ & $\begin{array}{c}\left(\sigma_{\mathrm{y}}\right)_{\mathrm{p}} \\
(\mathrm{MPa})\end{array}$ & $\begin{array}{c}\left(\tau_{\mathrm{xy}}\right)_{\mathrm{p}} \\
(\mathrm{MPa})\end{array}$ & $\begin{array}{c}\left(\sigma_{\mathrm{x}}\right)_{\mathrm{e}} \\
(\mathrm{MPa})\end{array}$ & $\begin{array}{c}\left(\sigma_{\mathrm{y}}\right)_{\mathrm{e}} \\
(\mathrm{MPa})\end{array}$ & $\begin{array}{c}\left(\tau_{\mathrm{xy}}\right)_{\mathrm{e}} \\
(\mathrm{MPa})\end{array}$ \\
\hline \multirow{5}{*}[0^{\circ}/90^{\circ}]{$_{\mathrm{s}}$} & 60 & -4.916 & -4.916 & -4.809 & -8.097 & -8.097 & -7.922 \\
& 70 & -4.917 & -4.917 & -4.811 & -9.447 & -9.447 & -9.243 \\
& 80 & -4.918 & -4.918 & -4.812 & -10.796 & -10.796 & -10.563 \\
& 90 & -4.920 & -4.920 & -4.814 & -12.146 & -12.146 & -11.884 \\
\hline & 60 & -8.307 & -6.526 & -11.329 & -14.126 & -10.696 & -17.318 \\
{$\left[30^{\circ} /-30^{\circ}\right]_{\mathrm{s}}$} & 70 & -8.414 & -6.620 & -11.432 & -16.480 & -12.479 & -20.204 \\
& 80 & -8.521 & -6.724 & -11.537 & -18.834 & -14.261 & -23.091 \\
& 90 & -8.605 & -6.824 & -11.559 & -21.189 & -16.044 & -25.977 \\
\hline \multirow{5}{*}[45^{\circ}/-45^{\circ}]{$_{\mathrm{s}}$} & 60 & -4.782 & -4.809 & -4.916 & -7.878 & -7.922 & -8.097 \\
& 70 & -4.784 & -4.811 & -4.917 & -9.191 & -9.243 & -9.447 \\
& 80 & -4.785 & -4.812 & -4.918 & -10.504 & -10.563 & -10.796 \\
& 90 & -4.787 & -4.814 & -4.920 & -11.817 & -11.884 & -12.146 \\
\hline & 60 & -15.472 & -13.523 & -14.266 & -25.902 & -23.582 & -26.435 \\
& 70 & -15.726 & -13.996 & -14.474 & -30.219 & -27.513 & -30.841 \\
& 80 & -16.561 & -15.206 & -14.706 & -34.536 & -31.443 & -35.247 \\
& 90 & -17.369 & -16.460 & -14.915 & -38.853 & -35.773 & -35.373 \\
\hline
\end{tabular}

\section{CONCLUSIONS}

In the present investigation; the thermal elastic, elasto-plastic and residual stresses in symmetric steel fiber reinforced thermoplastic laminated composite plates with a central circular hole under uniform temperature effect were performed by using finite elements method (FEM). Thermoplastic laminated composite plates were assumed to be simply supported and the Tsai-Hill theory was used as a yield criterion. For this purpose a general-purpose software code ANSYS was used during the solution. From the study results presented it can be concluded that:

1. The magnitudes of the elastic, elasto-plastic, residual stress and equivalent plastic strain are increased depending on increasing of uniform temperature value.

2. Stacking sequence and orientation angles of laminated plates clearly affect thermal stress components.
3. The uniform temperature causes plastic yielding in the symmetric cross-ply $\left[0^{\circ} / 90^{\circ}\right]_{\mathrm{s}}$, and angle ply $\left[30^{\circ} /-30^{\circ}\right]_{\mathrm{s}},\left[45^{\circ} /-45^{\circ}\right]_{\mathrm{s}},\left[60^{\circ} /-60^{\circ}\right]_{\mathrm{s}}$ laminated plates.

4. The magnitudes of the thermal stress components at the upper and lower layers of symmetric laminates are the same.

5. The selected uniform temperature values produce residual stress all stacking sequence of plates.

6. The magnitude of the equivalent plastic strain for the cross-ply $\left[0^{\circ} / 90^{\circ}\right]_{s}$, and angle ply $\left[45^{\circ} /-45^{\circ}\right]_{s}$ laminated plates is higher than that of angle ply $\left[30^{\circ} \%-30^{\circ}\right]_{s},\left[60^{\circ} \%-60^{\circ}\right]_{s}$.

\section{REFERENCES}

1. Y.M. Haddad, Advanced Multilayered and FibreReinforced Composites, Kluwer Academic Publishers, Netherlands, 1998.

2. O. Sayman, Elastic- plastic and residual stresses in symmetric thermoplastic laminated plates under a linear thermal loading. Composite Science and 
Technology, 62, 1231-1238 (2002).

3. R.M. Jones, Mechanics of Composite Materials, Taylor \& Francis Inc., USA, 1999.

4 N. Noda, R.B. Hetnarski and Y. Tanigava, Thermal Stresses, Lastran Corporation, Rochester, NY. USA, 2000.

5. C.H. Wang, L.R.F. Rose, R. Callinan and A.A. Baker, Thermal stresses in a plate with a circular reinforcement, Int. Journal of Solids and Structures, 37, 4577-4599 (2000).

6. M. Akay and S. Ozden, Measurement of residual stresses in injection moulded thermoplastics. Polymer Testing. 13, 323-354 (1994).

7. O. Saymarı and H. Callıglu, An elastic-plastic stress analysis of thermoplastic composite beams loaded by bending moments. Composite Structures, 50, 199-205 (2000).

8. O. Sayman and U. Esendemir, An elastic-plastic stress analysis on a thermoplastic composite beam of arbitrary orientation supported from two ends acted upon with a force at the midpoint, $J$. of Reinforced Plastics and Composites, 21, 473-485 (2002).

9. G. Jeronimidis and A.T. Parkyn, Residual stress in carbon fiber-thermoplastic matrix laminates, $J$. of Composite Materials, 22, 401-415 (1998).

10. O. Sayman and M. Kayrici, An elastic-plastic stress analysis in a thermoplastic composite cantilever beam, Composite Science and Technology, 60, 623-631 (1999).

11. M. Senel, H. Akbulut and M. Toparlı, Residual Stress analysis in symmetric thermoplastic laminated plates under thermal loads: analytic solution Journal of Thermoplastic Composite
Materials, 17, 481-507 (2004).

12. D.D.L. Chung, Thermal analysis of carbon fiber polymer-matrix composites by electrical resistance measurement, Thermochimica Acta, 364, 121-132 (2000).

13. M. Gigliotti, F. Jacquemin and A. Vautrin, On the maximum curvatures of $0 / 90$ plates under thermal stress, Composite Structures, 68, 177-184 (2005).

14. O. Sayman, M. Belevi and M. Duranay, Thermal stress analysis and residual stresses in a thermoplastic composite beam, $J$. of Reinforced Plastics and Composites, 22, 67-81 (2003).

15. Y.M. Shabana and N. Noda, Thermo-elasto-plastic stresses in functionally graded materials subjected to thermal loading taking residual stresses of the fabrication process into consideration, Composites: Part B, 32, 111-121 (2001).

16. H. Ji-Fan, Thermoelastic analysis of laminated plates including transverse shear deformation effects, J. Composite Structures, 30, $51-59$ (1995).

17. N.B. Bektas and O. Sayman, Elasto-plastic stress analysis in simply supported thermoplastic laminated plates under thermal loads, Composite Science and Technology, 61, 1695-1701 (2001).

18. M.K. Apalak, K. Aldas and F. Sen, Thermal nonlinear stresses in an adhesively bonded and laserspot welded single-lap joint during laser-metal interaction, J. Materials Processing Technology, 142, 1-19 (2003).

19. ANSYS. The general-purpose finite element software. Documentation.

20. S. Moaveni, Finite element analysis: Theory and application with ANSYS, $2^{\text {nd }}$ edition. Pearson Education. Inc. New Jersey. USA, 2003. 